\title{
Introducing emergency contraception in Bangladesh: A feasibility
} study

M.E. Khan

Population Council

Sharif M.I. Hossain

Population Council

Follow this and additional works at: https://knowledgecommons.popcouncil.org/departments_sbsr-rh

Part of the Demography, Population, and Ecology Commons, Family, Life Course, and Society Commons, and the Maternal and Child Health Commons How does access to this work benefit you? Let us know!

\section{Recommended Citation}

Khan, M.E. and Sharif M.I. Hossain. 2001. "Introducing emergency contraception in Bangladesh: A feasibility study," FRONTIERS Research Update. Dhaka: Population Council. 


\section{Introducing \\ Emergency Contraception in Banaladesh: A feasibilitv studv}

\section{Background}

In Bangladesh approximately 1.2 million pregnancies (31percent) are unplanned each year despite the Bangladesh Family Planning Program's intense efforts during the past 30 years to help couples to achieve their reproductive goals. Nearly 50 percent of couples do not use any contraceptive method, while 10.3 percent of couples use traditional methods and 15 percent have unmet needs for family planning (BDHS 2000) (Table 1).

Approximately 28,000 maternal deaths occur every year in Bangladesh due to pregnancy and delivery-related complications, while many more women suffer major physical and psychological injuries. Available statistics indicate an increase in Menstrual Regulation (MR) and abortions, and most of these are performed by untrained practitioners under unhygienic conditions. The official estimate indicates that about $120,000 \mathrm{MR} /$ abortions are performed every year, but unofficial estimates put it as high as 800,000 (Akhter 1986 and Rochat et al. 1981). Many of these $\mathrm{MR} /$ abortions result in serious maternal morbidities and/or deaths. According to Kamal

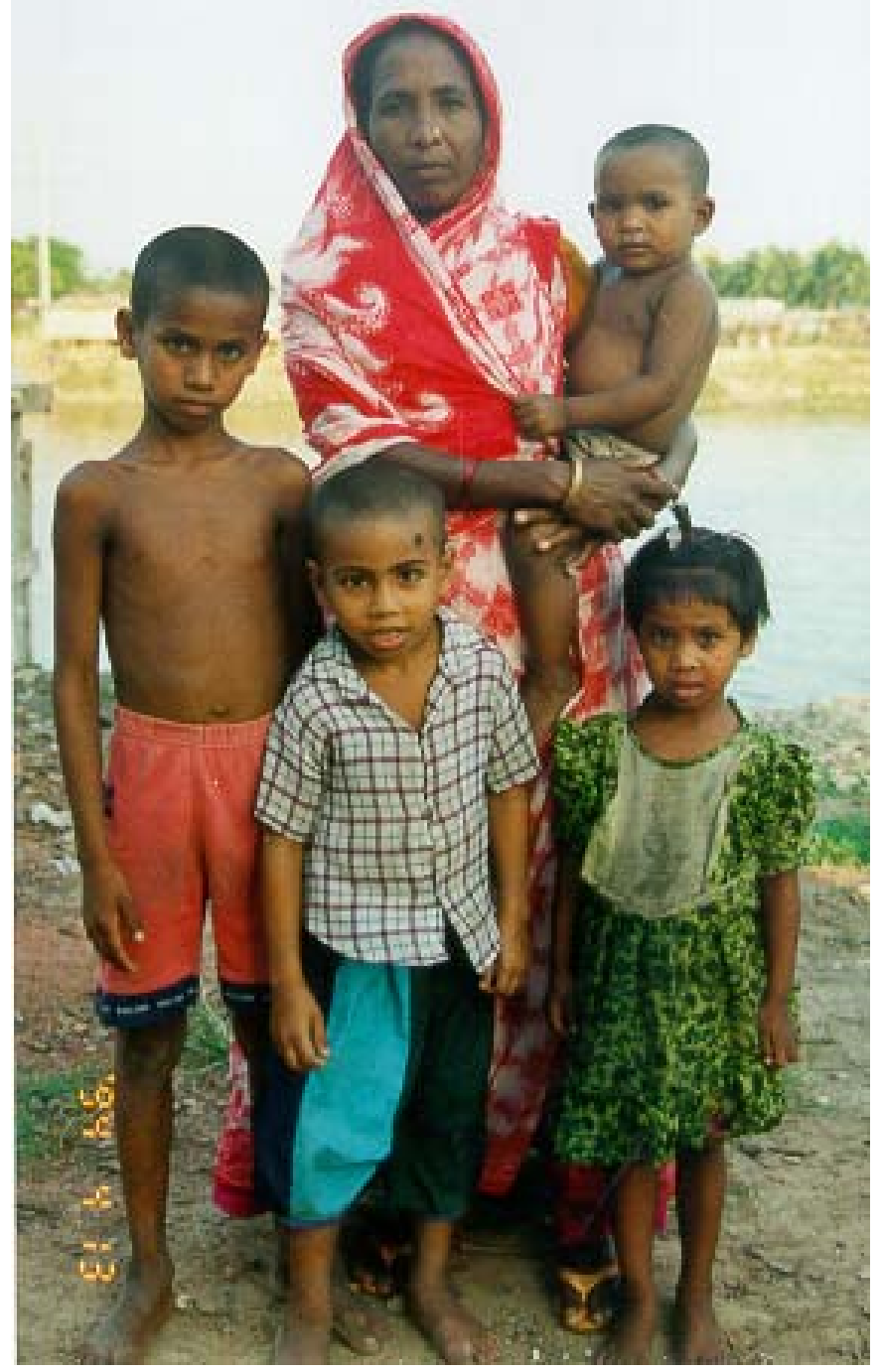

A woman with her children (1993), approximately 8,000 women in Bangladesh die each year due to abortion-related complications. 


\section{Emergency Contraception as Reproductive Health Intervention}

Emergency Contraception (EC) is an important technical innovation that provides women a chance to avoid unwanted pregnancy if unprotected intercourse occurs. It is not a regular family planning method and therefore should be used only as backup support to avoid unwanted pregnancy when a contraceptive has not been used or regular family planning methods fail, such as condom leakage or missing oral contraceptive pills. In Bangladesh, EC is relatively unknown by both providers and potential users. Currently, the family planning program does not promote EC.
Table 1: Bangladesh Demographic \& Family Planning Profile
Total population

Women aged 10-49

Adolescent girls (10-19)

Currently married women

(CMW) in reproductive age

CMW using any FP method

Couples using traditional

F. P. methods

Couples with unmet need

Couples not using any FP

method

Unwanted pregnancies
123 million

37.5 million

13.6 million

22.8 million

12.3 million

2.4 million

3.4 million

10.5 million

1.2 million
Source: BBS 1997 and BDHS 2000

Introducing emergency contraception in the national family planning program could substantially reduce unwanted pregnancies and as result, MR/abortions should also decrease. Because $\mathrm{MR} /$ abortions in Bangladesh significantly contribute to high maternal morbidity/mortality, introducing EC could be an important reproductive health intervention to provide couples with a back-up support to prevent unwanted pregnancy. Emergency contraception could also contribute significantly in reducing psychological worries and the health risks associated with unwanted pregnancies, MR and abortions.

\begin{tabular}{|c|c|c|}
\hline Brand Name & $\begin{array}{c}\text { Dose 1 } \\
\text { (within } 72 \\
\text { hours of } \\
\text { unprotected } \\
\text { intercourse) }\end{array}$ & $\begin{array}{c}\text { Dose } 2 \\
\text { (after } 12 \text { hours } \\
\text { of first dose) }\end{array}$ \\
\hline $\begin{array}{l}\text { Low-dose pills } \\
\text { Shukhi } \\
\text { Marvelon } \\
\text { Femicon } \\
\text { Nordette } 28 \\
\end{array}$ & $\begin{array}{l}4 \text { pills } \\
\end{array}$ & $\begin{array}{l}4 \text { pills } \\
\end{array}$ \\
\hline $\begin{array}{l}\text { Standard-dose pills } \\
\text { Combination } 5 \\
\text { Ovastat } \\
\text { Lyndiol } \\
\end{array}$ & 2 pills & 2 pills \\
\hline $\begin{array}{l}\text { Progestin-only pills } \\
\text { Postinor } 2\end{array}$ & $\begin{array}{c}\bullet \\
1 \text { pill }\end{array}$ & $\begin{array}{c}\bullet \\
1 \text { pill }\end{array}$ \\
\hline
\end{tabular}

Two methods of emergency contraception are available:

- Emergency Hormonal Contraception increased doses of birth control pills

- Insertion of an intrauterine device (IUD)

Emergency Contraceptive Pills (ECPs) are increased doses of "regular" oral contraceptives taken in two doses. The most common ECPs are "combination pills" that contain estrogen and progestin (synthetic hormones like the ones produced by a woman's body). However, recent studies indicate that ECP, containing progestin only are more effective and have less side effects (e.g. Postinor 2).

ECP works only if a woman is not already pregnant from earlier intercourse. It prevents pregnancy by preventing or delaying ovulation 
(release of egg) thus preventing fertilization, implantation or transportation of sperm and/or ova. It is not an abortifacient. It neither induces abortion nor harms an existing pregnancy.

Several kinds of oral contraceptive pills (OCPs) can be used as ECPs (Table 2). The pills are taken in two doses, 12 hours apart. The first dose must be taken within 72 hours of unprotected intercourse. The earlier it is taken the more effective it will be. The same type of pill must be used for both doses.

\section{Introducing Emergency Contraception in Bangladesh}

Though dedicated ECPs have not yet been introduced in the Bangladesh Family Planning Program, several kinds of oral contraceptive pills are available in Bangladesh that can be used as emergency contraception (Table 2). Specially packaged EC pills (Postinor 2) are available in the market and are being promoted through the private sector at a cost of Taka 24 (\$0.45) per packet.

The Directorate of Family Planning in collaboration with the Population Council's Frontiers in Reproductive Health Project, Pathfinder International and John Snow Inc. (JSI), is conducting this feasibility study to develop, test and document operational details for introducing emergency contraception as a back-up support for existing family planning methods. More specifically, the study intends to:

- Determine the acceptability and appropriate use of ECP among Bangladesh women

- Identify the most appropriate and cost-effective service delivery model to make ECP accessible

- Test and document how best ECP could be introduced without adversely affecting the use of other family planning methods

This report is an interim update of what the study has accomplished so far.

Research Design: The study has three phases. The first phase is a diagnostic study using qualitative methods to assess existing practices that women use to avoid pregnancy if unprotected intercourse occurs, community perceptions of emergency contraception and their interest in using it. The first phase of the study also assesses FP providers' knowledge of emergency contraception and other FP methods, assesses their counseling skills, and develops educational brochures and counseling aids on emergency contraception. The second

Table 3: Study Design

\begin{tabular}{|l|ccc|}
\hline \multicolumn{1}{|c|}{ Interventions } & $\begin{array}{c}\text { Group } \\
\mathrm{A}\end{array}$ & $\begin{array}{c}\text { Group } \\
\mathrm{B}\end{array}$ & $\begin{array}{c}\text { Group } \\
\mathrm{C}\end{array}$ \\
\hline $\begin{array}{l}\text { EC counselling and } \\
\text { brochure on EC }\end{array}$ & Yes & Yes & No \\
\hline Two packets of EC pills & No & Yes & No \\
\hline
\end{tabular}
phase is an intervention phase (training of providers and providing ECP services), while the third phase will be an impact assessment and dissemination activities.

A multi-factorial, control group, longitudinal survey design has been developed to study the effects on acceptability and use of ECP. The study tests the relative effectiveness of two 
alternative service delivery models for providing ECPs. In the first study group (A), all family planning clients except IUD and sterilization acceptors are receiving counseling about ECPs and an informational brochure in addition to other contraceptive methods. In the second group (B), the same types of clients are receiving counseling about ECPs, an informational brochure on ECPs and in addition, two packets of ECPs to use, if needed. The third group (C) is the control group (Table 3).

\section{Findings}

Diagnostic Phase: A total of 53 focus group discussions (FGDs) (17 male groups and 36 female groups) and 94 in-depth interviews (32 men and 62 women) were conducted with currently married men and women. A total of 428 persons (308 women and 120 men) participated in the FGDs.

The analysis of the qualitative data revealed that people do not have any knowledge of emergency contraception. However, many women practice various traditional methods to protect themselves from unwanted pregnancy, if unprotected intercourse occurs. Some of the frequently used traditional practices include passing urine after intercourse, quickly standing up after sex and walking or jumping, taking high doses of red (iron) pills and an inappropriate dose of white (contraceptive) pills. A few women also mentioned drinking salt water or tamarind water on an empty stomach.

The study also revealed that a substantial number of women use harmful traditional methods to terminate unwanted pregnancies. Such methods include inserting roots into the uterus, eating caterpillar with banana, and using other procedures from untrained providers. In general, both men and women believed that the incidence of $\mathrm{MR} /$ abortion is increasing, but

\section{Voices From The Field}

- "I just get up from bed after sex and start jumping. It does not allow 'baby' (semen) to go inside me."

- "Women pass urine after unprotected intercourse to wash out semen."

- "First thing women think is to abort unwanted pregnancy. Some of them may not be able to do it because of husband's opposition or because of religious reasons but it worries them a lot -- how they will feed the child, how they will marry if the child is a girl."

- "Insertion of root to abort pregnancy is common. Kabiraj charge 40 Taka for it. It works up to 6 months of pregnancy."

- "Listen apa, paying Taka 15-20 is much easier than paying 200 or more after getting pregnant from unprotected sex."

- "Apa, you would not know worries of unwanted pregnancy. After unprotected sex the month becomes too long to pass (meant waiting for next MC)."

- "Women have to go through a lot of tension and worries after each unprotected sex. They will love to have ECP, even if it cost 20 Taka."

- "My husband lives outside. Often he comes home unplanned. When he comes he has sex many times. If I resist he forces it. That month is full of worries as he does not like to use a condom."

- "Sometime I do not have pill. Even in such situation my husband does not like to use condom. He says, "I can't wait to have sex till you get the method." What we can do in such situation."

the dependence on Kabiraj (traditional healers) has declined. None of the women in the discussion groups could distinguish between MR and abortion. 
Most women believed that unprotected intercourse is common. The reasons they listed include: condom failure (bursting), missing pills or injections, occasional shortage of pills, unplanned sex (husband suddenly comes to house from outside), and forced sex. Most women felt that the availability of ECPs would be a great help to women since unprotected sex is frequent and often they do not have much control over their sexual relations. In most of the FGDs, participants agreed that women would be willing to pay for ECP. In 44 out of 53 FGDs conducted, Taka 1015 emerged as the consensus price for one encounter of unprotected intercourse.

In 43 of the 53 FGDs, the participants didn't feel that introducing emergency contraception would reduce the use of other FP methods. Interestingly, in 39 FGDs some of the participants felt that easy availability of emergency contraception pills might increase pre- or extramarital sex.

Providers Baseline Survey: The service providers are mainly paramedics, community health workers and their supervisors working in government and NGOs family planning program. While paramedics are trained to provide both curative as well as clinical contraceptive services (insertion of IUD and provision of DMPA injection), the community health workers are mainly responsible for promoting family planning and distributing OCP and condoms. Ninety-two percent of the service providers were female. About one-fourth of the service providers were above 40 years, two-fifth

\section{Figure 1: Perceptions of FP Workers on Emergency Contraceptive Pills}

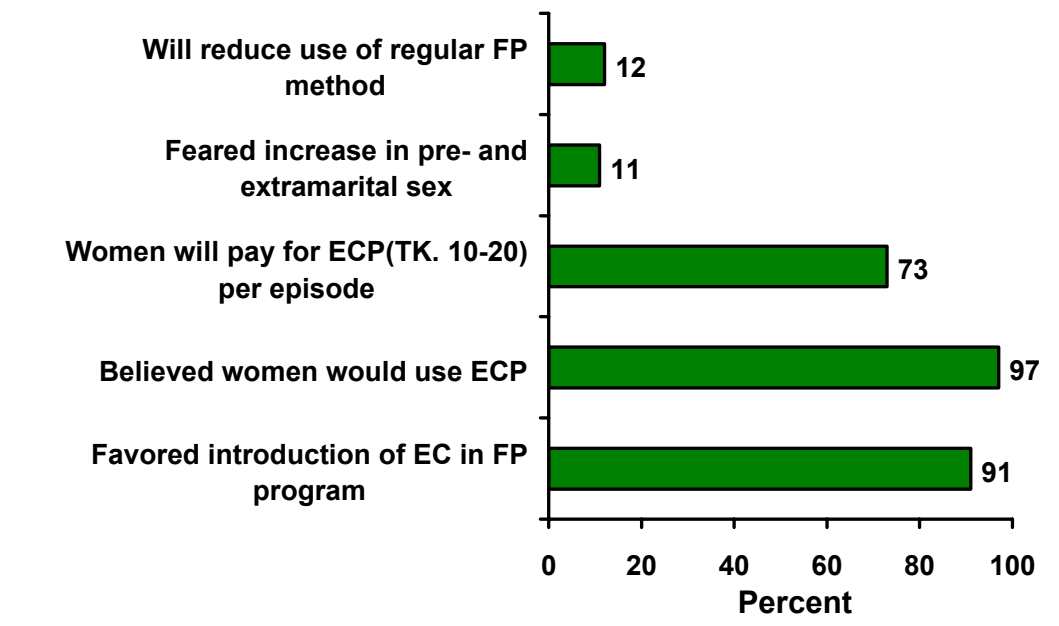

in 30-39 years and the rest one-third were below 30 years. About 95 percent of the service providers had received one or more times training on family planning.

Before orienting the providers about emergency contraception, all FP workers and their immediate supervisors in the study areas $(\mathrm{N}=293)$ were individually interviewed to assess their knowledge and perceptions of EC, use of OCP, and counseling skills. The main findings that emerged from the interviews indicate that:

- The workers are aware that unwanted pregnancies are common. The main reasons for these unwanted pregnancies identified by the providers include the non-use of family planning methods (46 percent), missing pills (87 percent) or due date of injection (31 percent), condom failure (74 percent), unexpected visit by husband (11 percent) and miscalculation of safe period (12 percent).

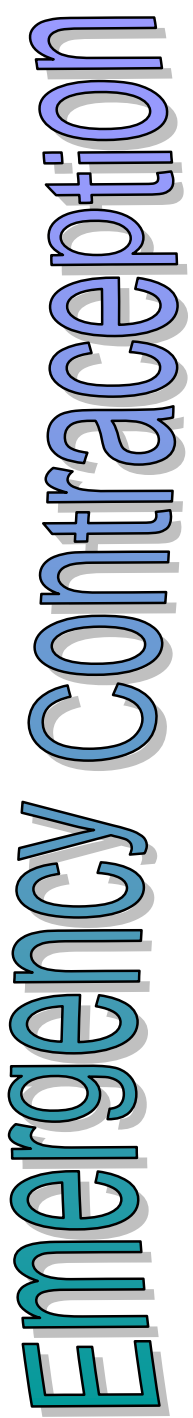


- The majority of the providers believe that a substantial proportion of unwanted pregnancies are aborted. Apart from MR, drugs from the pharmacy (52 percent), herbal medicine (58 percent) and insertion of roots or similar other harmful methods ( 56 percent) are frequently used to abort unwanted pregnancies.

- Out of the 293 workers interviewed, only 64 (22 percent) were vaguely aware that Shukhi (OCP) could be used as an emergency contraception. Only four of them were aware of the correct dose, number of pills in each dose, interval between the two doses and time limit within which ECP must be taken. None mentioned any other brand of pills that could be used as ECP.

- About two-thirds of workers reported that women frequently contact them for advice after unprotected sex. The number of such cases varies between two and six per month. Most of the providers supported the introduction of EC in the family planning program (Figure 1).

- Analysis also revealed several misconceptions among the workers about OCP use, lack of knowledge of what could be done if a woman misses pills for two consecutive days, and relatively poor counseling skills. Many believed that long-term use of OCP could be harmful, and only 21 percent knew that OCP could be used for a woman's entire reproductive life.

Training of Providers and Post-Training Evaluation: All FP workers and their supervisors were given a two-day comprehensive training on various aspects of family planning. The topics covered in the training included a demographic scenario of Bangladesh, a contraceptive technology update, counseling skills, emergency contraception, ethical issues and objectives of the project. In the control group, however, no discussions were held on emergency contraception and the project activities. They were told that the training was a part of a regular re-orientation program.

Table 4: Providers' knowledge of available OCPs that could be used as ECP

\begin{tabular}{|c|c|c|c|c|c|}
\hline & \multicolumn{5}{|c|}{ OCP brands commonly available in Bangladesh } \\
\hline & Shukhi & Nordette 28 & Femicon & Marvelon & Ovastat \\
\hline $\begin{array}{l}\text { Percentage of workers named the } \\
\text { brand as possible ECP }(n=239)\end{array}$ & 100 & 94 & 96 & 82 & 75 \\
\hline $\begin{array}{l}\text { Percentage of providers who knew* } \\
\text { how ECP is correctly used** }\end{array}$ & 97 & 93 & 97 & 88 & 79 \\
\hline * $\quad$ Based on those workers who nar & the speci & brand & & & \\
\hline
\end{tabular}

Before organizing the training, a trainer's manual and teaching aid transparencies were developed, trainers were oriented on objectives and the expected outcome from each session, and educational brochures on EC were developed for the providers and clients in the local language (Bengali). Providers were trained in groups of 20-25 workers. The training was organized at Government's Family Welfare Visitor Training Institute (FWVTI), Tangail. The Assistant Director of Clinical Contraception from District Family Planning Office and many faculties (trainers) of the institute, were involved in imparting the training. All of the district level and 
thana (Lowest administrative unit) level program managers were also oriented about the project activities and emergency contraception pills.

After the two-day training, a brief post-training evaluation test was administrated to each worker. An analysis of this data revealed a significant increase in providers' knowledge, and in general, they were able to acquire adequate knowledge to provide EC services (Table 4) and effective counseling skills (Figure 2). In the baseline survey, only 4 out of 293 providers knew how OCP could be correctly use as ECPs. After the training, almost 100 percent had acquired this knowledge.

The evaluation also revealed that some providers were still confused about OCP use

Figure 2: Percentage of Correct Responses given by Providers Who Participated both in Baseline Survey and Post-training Test

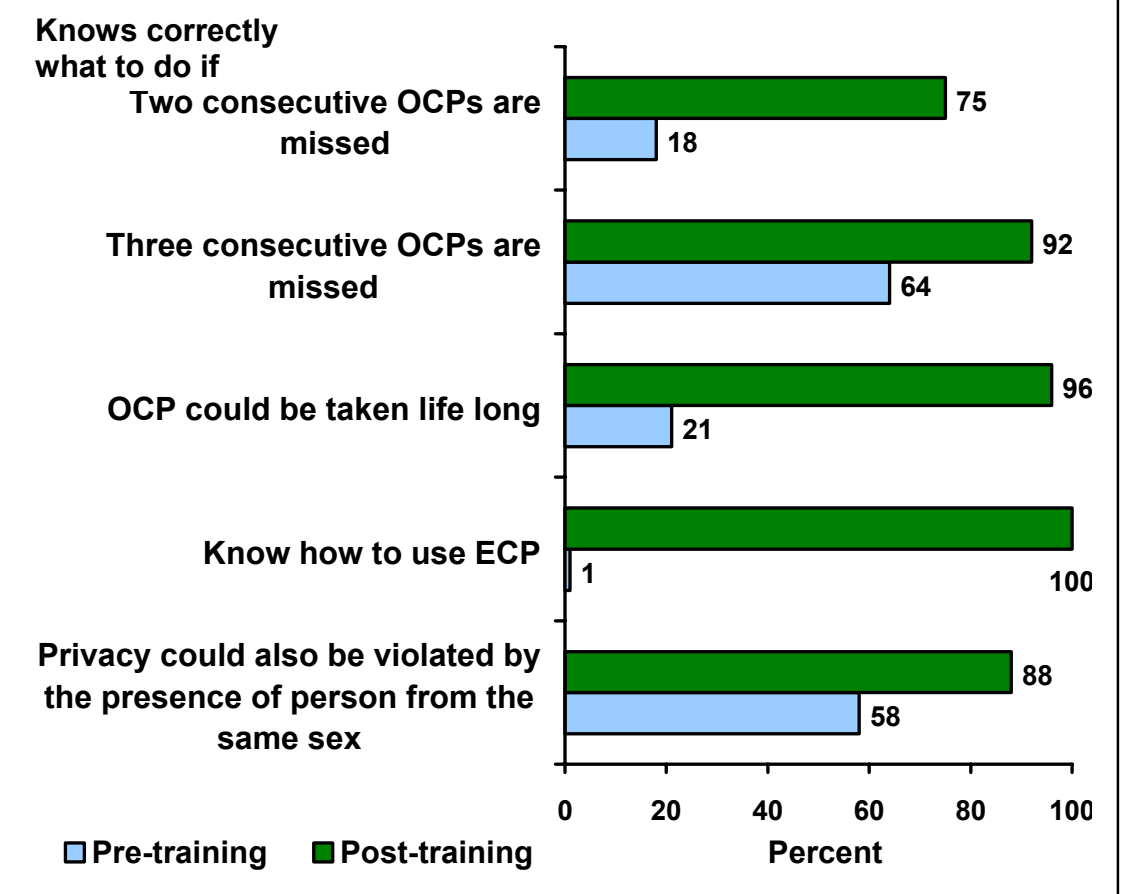

and the correct usage of specific brands of OCP as an ECP. A total of 49 providers were identified who need additional training on using OCP, and they received remedial training.

One month after the first training, a second half-day refresher training of all workers participating in the study was organized. The purpose of the second training was to discuss their experience in providing EC services and clarify their questions, if any. A final evaluation of the providers' knowledge, assimilation of their knowledge, and its use in provision of services will be done in March 2001. A follow-up survey of women to assess acceptability and use of EC will be carried out in July 2001. Service statistics indicate that in less than four months 1103 women in group (A) have been provided with information on emergency contraception as well as ECPs on prophylactic basis. An almost equal number (1190) of women have been provided with information on emergency contraception in group (B) and have been advised to come back for ECP supplies, if needed.

\section{Lessons Learned to Date}

- 293 providers received the contraceptive technology update, counseling skills, and emergency contraception training. The study also oriented 25 program managers about EC.

- The two-day training model developed for re-orienting the workers in FP and the use of EC is sufficient to teach providers about EC. 
- The trainer's manual developed for this orientation has been tested and found useful.

- The educational brochures on EC developed for providers and clients have been reviewed by the Project Management Committee and found useful in the field. The Bangla version of the brochures is now being widely distributed among clients.

- Both the diagnostic study with community members and the baseline survey of providers indicate that emergency contraception will have high acceptability among women. Initial results from the field show that 1103 women have been provided with emergency contraception pills on prophylactic basis (Group A) and 1190 women have been educated about emergency contraception in demand areas (Group B) during the first four months.

- Women are willing to pay between Taka 10-15 for each packet of ECP to prevent an unwanted pregnancy from an episode of unprotected sex. This willingness to pay for emergency contraception should be validated by charging price for the supplies of the method.

- Providers need training in counseling skills and contraceptive technology updates to remove some of their misconceptions and lack of knowledge about the use of OCP. Such training may reduce the discontinuation of OCP.

\section{References}

Akhter, Halida. H. 1986. "Medical Practice after Legalization of Abortion: Bangladesh." Prevention and Treatment of Contraceptive Failure, U. Landy and S. S. Ratnam (eds.). New York: Plenum Press.

Bangladesh Bureau of Statistics. 1997. Gender Statistics in Brief 1997. Monograph. Dhaka: Bangladesh Bureau of Statistics.

Kamal, H., A. Hussain , S. F. Begum, and G. M. Kamal. 1993. Prospects of Menstrual Regulation Services in Bangladesh: Results of an Operations Research. Monograph. Dhaka: Bangladesh Association for Prevention of Septic Abortion (BAPSA).

NIPORT, Mitra and Associates and Measure/DHS+IRC-Macro International Inc. 2000. Bangladesh Demographic and Health Survey 1999-2000: Preliminary Report. Dhaka, Bangladesh: NIPORT, Mitra and Associates and Measure/DHS+ ORC-Macro International Inc.

Rochat, R. W., S. Jabeen, M. J. Rosenberg, A. R. Measham, A. R. Khan, M. Obaidullah and P. Gould. 1981. "Maternal and Abortion Related Deaths in Bangladesh, 1978-79." International Journal of Gynaecology and Obstetrics 19: 155-164.

\section{Suggested Citation}

Khan, M. E. and Sharif Mohammed Ismail Hossain. Introducing Emergency Contraception in Bangladesh: A Feasibility Study. Research Update 1, March 2001. Dhaka, Bangladesh: Population Council/FRONTERS.

This Research Update has been prepared by M.E. Khan and Sharif Mohammed Ismail Hossain, Population Council, Office Address: House CES (B) 21, Road 118, Gulshan, Dhaka 1212, Bangladesh. Tel: 8821227,8826657,Fax: 8823127,E-Mail:frontiers@popcouncil.bangla.net

The study is being carried out in collaboration with the Directorate of Family Planning, Government of Bangladesh (Dr. Jahiruddin Ahmed), Pathfinder International/RSDP (Dr. Shabnam Shahnaz)) and John Snow Inc./UFHP (Dr. Nadira Sultana).

This publication was made possible through support provided by U. S. AGENCY FOR INTERNATIONAL DEVELOPMENT (USAID) under the terms of Cooperative Agreement No. HRN-A-00-98-00012. The opinions expressed herein those of authors and do not necessarily reflect the views of USAID. 